\title{
A comparison of Rayleigh and sodium lidar temperature climatologies
}

\author{
P. S. Argall and R. J. Sica \\ Dept. of Physics and Astronomy, The University of Western Ontario, London, Ontario, Canada \\ Received: 16 June 2006 - Revised: 3 January 2007 - Accepted: 15 January 2007 - Published: 1 February 2007
}

\begin{abstract}
Temperature measurements from the PCL Rayleigh lidar located near London, Canada, taken during the 11 year period from 1994 to 2004 are used to form a temperature climatology of the middle atmosphere. A unique feature of the PCL temperature climatology is that it extends from 35 to $95 \mathrm{~km}$ allowing comparison with other Rayleigh lidar climatologies (which typically extend up to about $85 \mathrm{~km}$ ), as well as with climatologies derived from sodium lidar measurements which extend from 83 to $108 \mathrm{~km}$. The derived temperature climatology is compared to the CIRA-86 climatological model and to other lidar climatologies, both Rayleigh and sodium. The PCL climatology agrees well with the climatologies of other Rayleigh lidars from similar latitudes, and like these other climatologies shows significant differences from the CIRA-86 temperatures in the mesosphere and lower thermosphere. Significant disagreement is also found between the PCL climatology and sodium lidar climatologies measured in the central and western United States at similar latitudes, with the PCL climatology consistently 10 to $15 \mathrm{~K}$ cooler in the 85 to $90 \mathrm{~km}$ region.
\end{abstract}

Keywords. Atmospheric composition and structure (Pressure, density, and temperature; Instruments and techniques; General or miscellaneous)

\section{Introduction}

Rayleigh-scatter lidar is a well established technique for measuring temperature in the middle atmosphere. This technique provides good altitude and temporal resolution measurements, although measurement accuracy is a function of altitude with measurements at greater altitudes having

$\overline{\text { Correspondence to: P. S. Argall }}$

(pargall@uwo.ca) larger statistical uncertainty than those at lower altitudes (Hauchecorne and Chanin, 1980).

The Purple Crow Lidar (PCL) (Sica et al., 1995, 2000; Argall et al., 2000) is a Sodium-Rayleigh-Raman lidar system, which operates from the Delaware Observatory near The University of Western Ontario in London, Canada. A unique feature of the PCL is the $2.6 \mathrm{~m}$ diameter liquid mirror telescope (LMT) used as the primary collecting optic in the lidar's receiver system. This mirror, coupled with the $12 \mathrm{~W}, 600 \mathrm{~mJ} / \mathrm{pulse}$, frequency-doubled YAG laser used in the PCL Rayleigh-Raman transmitter, gives the PCL a high power-aperture product. This high power-aperture product means that enough photon counts are obtained in a few hours of measurements to allow the temperature integration to be initialized at altitudes above $105 \mathrm{~km}$. It is important to note that the top $10 \mathrm{~km}$ are removed from all temperature profiles used to form the PCL climatology, reducing the effect of the initialization of the temperature retrieval integration (Sica et al., 1995). Nightly averaged PCL temperature profiles routinely extend to $95 \mathrm{~km}$ even after removal of the top $10 \mathrm{~km}$. Only temperatures measured with the PCL Rayleigh system are used to form the climatology reported here as the number of Rayleigh temperature measurements far exceeds those of either the PCL Raman or Sodium systems.

The temperature climatology of the middle atmosphere has been studied for several decades. This study adds to previous work reported by Clancy et al. $(1989,1994)$, Leblanc et al. (1998), She et al. (2000), States et al. (2000), Randel et al. (2004), and others, in particular those studies made by ground based lidar systems. One important difference in this study is a single measurement technique is used over a much larger region of the atmosphere than in previous studies, which had to combine multiple techniques to span a similar height range. Currently the CIRA-86 (Fleming et al., 1990) model is used as a reference for the middle atmosphere temperatures, although it is known to that this reference is in need of updating due to differences with newer

Published by Copernicus GmbH on behalf of the European Geosciences Union. 
Table 1. Instrument specifications for the PCL lidar.

\begin{tabular}{ll}
\hline Data Set & PCL (Rayleigh) \\
Longitude & $81.4^{\circ} \mathrm{W}$ \\
Latitude & $42.9^{\circ} \mathrm{N}$ \\
Emitted/Received wavelength, nm & $532 / 532$ \\
Laser Energy, mJ/pulse & 600 \\
Laser Pulse Repetition frequency, pulses/s & 20 \\
Telescope Area, $\mathrm{m}^{2}$ & 5.3 \\
Field of view, $\mathrm{mrad}$ & 0.39 \\
\hline
\end{tabular}

climatologies based on lidar measurements. In general previous work shows reasonable agreement in the middle and upper stratosphere with the CIRA-86 model, but significant differences in the mesosphere and lower thermosphere.

\section{Procedure for generating the climatology}

The PCL Rayleigh lidar has been operated on a routine basis since the beginning of 1994, except for a few periods of down time, most notably 2001. Relevant characteristics of the system are given in Table 1. The climatology used in this study is determined from the distribution of nightly averaged temperature profiles as shown in Table 2. There is a large disparity between the number of measurements in winter and in summer; this is due primarily to less favourable observing conditions in the winter months. The average integration time for the measurements used in this study is $5.4 \mathrm{~h}$.

The PCL climatology is based on the nightly average temperature profiles for all of the nights on which measurements of sufficient quality exist from the beginning of 1994 to the end of 2004. Nightly averaged measurements were judged to be of sufficient quality if the measurement signal-to-noise ratio was greater than 2 at the minimum altitude specified for temperature integration initialization, $95 \mathrm{~km}$. The following procedure was used to determine the average temperature profile for individual nights.

1. The raw photon-count profiles recorded by the PCLRayleigh lidar ( $24 \mathrm{~m}$ altitude resolution and $1 \mathrm{~min}$ time resolution) were individually examined and marked bad if a profile had low signal, high background, or any other abnormality. Profiles marked bad in this way were not included further in the analysis.

2. Individual photon-count profiles were corrected for detector system non-linearities (Sica et al., 1995). The minimum altitude above which an accurate correction could be made was established and data below this altitude removed. This procedure determined the lower altitude limit for the temperature profile.
Table 2. Parameters used to form the PCL Rayleigh temperature climatology.

\begin{tabular}{|c|c|}
\hline Vertical resolution used, $\mathrm{km}$ & 1 \\
\hline Altitude range used, $\mathrm{km}$ & $35-95$ \\
\hline Estimated error at midrange $(65 \mathrm{~km}), \mathrm{K}$ & $\sim 0.15$ \\
\hline Estimated statistical error at top, $\mathrm{K}$ & 5 \\
\hline First year used & 1994 \\
\hline Last year used & 2004 \\
\hline Number of profiles: total & 453 \\
\hline January & 6 \\
\hline February & 17 \\
\hline March & 15 \\
\hline April & 20 \\
\hline May & 55 \\
\hline June & 68 \\
\hline July & 86 \\
\hline August & 84 \\
\hline September & 28 \\
\hline October & 36 \\
\hline November & 22 \\
\hline December & 16 \\
\hline 1994 & 47 \\
\hline 1995 & 50 \\
\hline 1996 & 24 \\
\hline 1997 & 19 \\
\hline 1998 & 88 \\
\hline 1999 & 63 \\
\hline 2000 & 51 \\
\hline 2001 & 2 \\
\hline 2002 & 60 \\
\hline 2003 & 38 \\
\hline 2004 & 11 \\
\hline
\end{tabular}

3. Photon-count profiles from each individual night were co-added over the entire observation period in time and to an altitude resolution of $1008 \mathrm{~m}$.

4. The background counts were calculated from the average photon count level between 120 and $176 \mathrm{~km}$, and then subtracted from the signal profile.

5. The photon-count profiles were corrected for range and ozone absorption using the method of Sica et al. (2001).

6. The corrected photon-count profiles were scaled to match the density profile of the CIRA-86 model in the altitude range 45 to $60 \mathrm{~km}$. This scaling yielded a wellscaled relative density profile. The relative density profiles were chopped at the highest altitudes so that the minimum signal-to-noise ratio was greater than 2 . This procedure determined the upper altitude limit of the density profile.

7. A relative pressure profiles was calculated by integrating the relative density profile using the hydrostatic 


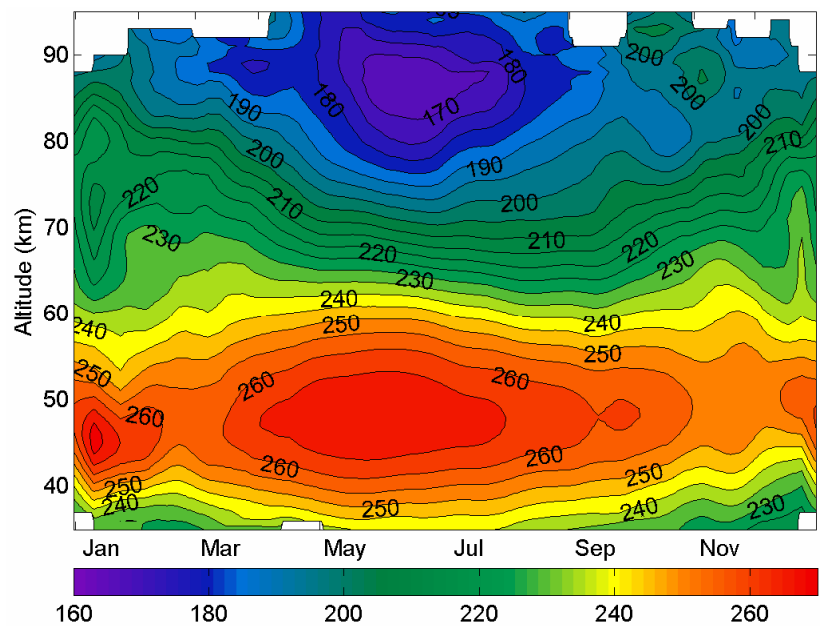

Fig. 1. Interpolated composite year of temperature measurements from the PCL Rayleigh lidar.

equation. The initial (top) pressure used for this integration was taken from the CIRA-86 model atmosphere.

8. The Ideal Gas Law was applied to the relative pressure and density profiles yielding an absolute temperature profile.

9. The calculated temperature profiles were smoothed with a 7 point, 3's and 5's, filter. A 3's and 5's filter is equivalent to filtering the data with a 5-point, then a 3-point running average. Numerically, the filter coefficients are found by the convolution of a vector of 3 ones with a vector of 5 ones (divided by 15 for normalization).

Temperature profiles calculated in this way are influenced by the CIRA pressure that was used to initiate the pressure integration. However, this error decreases exponentially with altitude below the integration start altitude. The top $10 \mathrm{~km}$ of each temperature profiles was removed in order to minimise this integration initialization effect. If necessary the top altitude was further reduced so that the statistical standard deviation, due to photon counting statistics, of the temperature is less than $6 \mathrm{~K}$ at the greatest altitudes (significantly less at lower altitudes).

Leblanc et al. (1998) present a study of the testing of Rayleigh lidar temperature retrieval routines. The data analysis routines used for the PCL climatology were validated in collaboration with Dr. Leblanc using this same procedure.

\section{Discussion of the climatology - the composite year}

The nightly averaged temperature profiles were used to form a composite year of measurements. Only temperature profiles extending to altitudes of at least $85 \mathrm{~km}$, after the top $10 \mathrm{~km}$ had been removed, were included in the composite

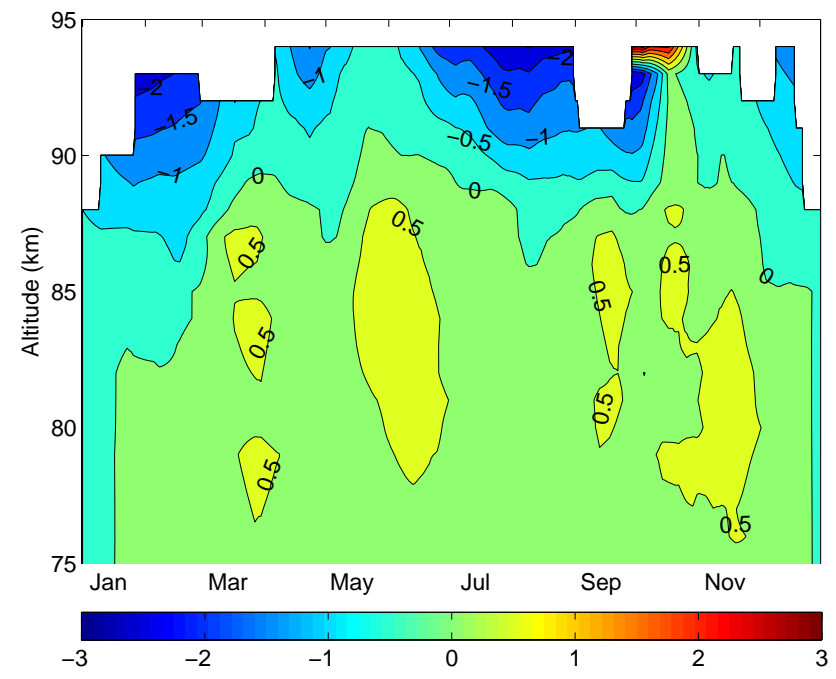

Fig. 2. Temperature differences between the PCL climatology seeded with the CIRA-86 model and the PCL climatology seeded with the CSU climatology.

year. For nights in the composite year on which multiple temperature measurements exist the temperature profiles from the individual nights were averaged together for inclusion in the composite year. Linear interpolation was used to fill in temperatures on nights where no measurements exist (122 nights). The resulting interpolated composite year was then filtered with a 33 day (full width) triangular filter (Fig. 1).

In most respects this climatology is similar to that presented by Leblanc et al. (1998) for the Observatoire de Haute Provence (OHP) and Centre d'Essais des Landes (CEL) lidars. These two lidars, which are operated by the Service d'Aéronomie du Centre National de la Recherché Scientifique (CNRS) France, are at similar latitudes $(44.0 \mathrm{~N})$ to the PCL $(42.9 \mathrm{~N})$, but about $85^{\circ}$ apart in longitude. The $\mathrm{OHP}+\mathrm{CEL}$ climatology extends $5 \mathrm{~km}$ lower than the PCL climatology $(30 \mathrm{~km})$, however its upper altitude is $10 \mathrm{~km}$ lower then the PCL climatology. Leblanc et al. (1998) also includes a climatology from the Colorado State University (CSU) sodium lidar $(40.6 \mathrm{~N})$ which has since been updated by She et al. (2000). This CSU temperature climatology extends from 83 to $105 \mathrm{~km}$. It is important to note that the PCL climatology overlaps the middle and upper parts of the OHP+CEL climatology as well as the lower $13 \mathrm{~km}$ of the CSU Na lidar climatology. The PCL temperature measurements in the lower thermosphere allow direct inter-comparison of these individual climatologies, particularly around $85 \mathrm{~km}$ altitude where the OHP+CEL and CSU climatologies have very little overlap.

The PCL climatology (Fig. 1) shows that the summer stratopause has a temperature maximum of $270 \mathrm{~K}$ in late May at $48 \mathrm{~km}$, some $2 \mathrm{~K}$ cooler and $1 \mathrm{~km}$ higher than determined by Leblanc et al. The winter stratopause is coldest $(253 \mathrm{~K})$ in early November at $51 \mathrm{~km}$, some $2 \mathrm{~K}$ colder and $4 \mathrm{~km}$ higher 
Table 3. Mesopause altitudes as determined from the PCL and CIRA-86 climatologies. PCL measurements for January to March as well as December do not extend to the mesopause. Cases where the mesopause determined by the PCL may be the lower of a double mesopause structure are indicated by an asterisk.

\begin{tabular}{|c|c|c|c|c|c|c|c|c|c|c|c|c|}
\hline \multirow[t]{2}{*}{ Mesopause altitude } & \multicolumn{12}{|c|}{ Month } \\
\hline & Jan & $\mathrm{Feb}$ & March & April & May & June & July & Aug & Sep & Oct & Nov & Dec \\
\hline PCL & $>87$ & $>93$ & $>89$ & 88 & 88 & 87 & 87 & 86 & 88 & $82 *$ & $82 *$ & $>90$ \\
\hline CIRA & 97 & 96 & 95 & 94 & 93 & 92 & 92 & 93 & 94 & 96 & 97 & 97 \\
\hline CIRA higher by & & & & 6 & 5 & 5 & 5 & 6 & 6 & 14 & 15 & \\
\hline
\end{tabular}

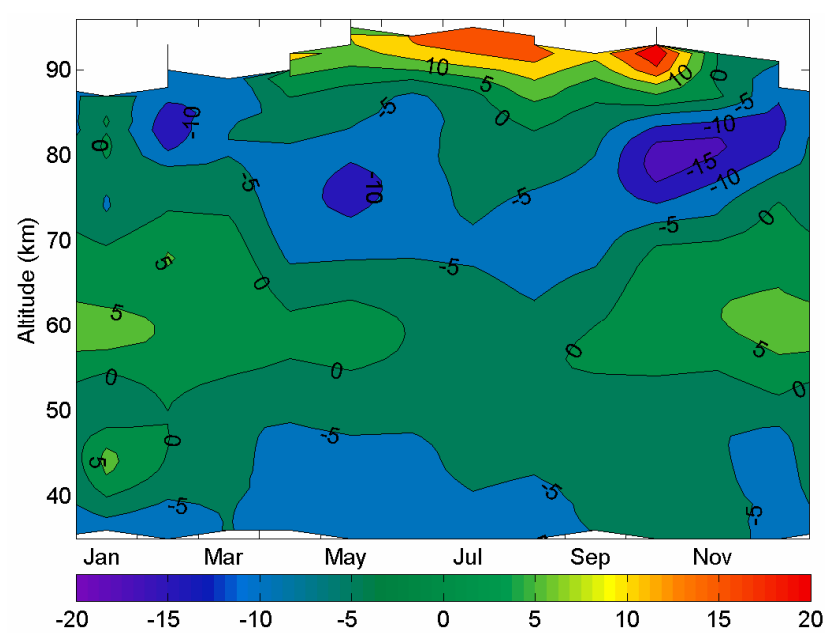

Fig. 3. Temperature difference between the PCL temperature climatology and CIRA-86.

than reported by Leblanc et al. The cold summer mesopause has a minimum temperature of $165 \mathrm{~K}$ in late May at $87 \mathrm{~km}$. The winter mesopause is above the top altitude of the PCL climatology; consistent with the CSU climatology, which shows the winter mesopause to be at about $103 \mathrm{~km}$ altitude.

The OHP+CEL and PCL climatologies all show a very clear temperature minimum at about $80 \mathrm{~km}$ in late October and early November; too low in altitude to be measured by the $\mathrm{Na}$ lidar. However, the CSU climatology shows the mesopause at this time of year at about $100 \mathrm{~km}$. Leblanc et al. (1998) suggest that the local minimum at $80 \mathrm{~km}$ is a direct consequence of mesospheric temperature inversions which, while occurring throughout the fall and winter, manifest themselves in the average temperature structure only in the fall. During the winter the inversions, which can have quite large amplitudes (Liu and Meriwether, 2004), show a higher degree of altitude variability and so are averaged out in the climatology.

Before discussing the PCL climatology in more detail it is instructive to quantitatively assess possible errors in the PCL climatology associated with the seeding of the pressure profile integration with a pressure from the CIRA model. To do this assessment a second climatology was formed using temperature profiles calculated so that the temperature at the top of the individual profiles matched that of the CSU climatology. This procedure was undertaken by selecting the integration start pressure such that temperature at the top of the profile was equal to the CSU climatology temperature. The differences between the CIRA and CSU climatologies at $103 \mathrm{~km}$, a typical altitude for PCL pressure integration initialization, varies from $0 \mathrm{~K}$ to about $15 \mathrm{~K}$ depending on the time of year. The difference between the PCL climatologies calculated using CIRA-86 and CSU climatology seeding for the individually nightly average temperature profiles is shown in Fig. 2. The temperature difference is typically less than $1 \mathrm{~K}$ at altitudes below $90 \mathrm{~km}$ and only slightly higher, typically below $2 \mathrm{~K}$ above $90 \mathrm{~km}$. Although this comparison does not give a definitive test of the accuracy of the temperature retrieval initialization, it does show that the PCL climatology is relatively insensitive to the seeding used in the retrieval, so long as the top $10 \mathrm{~km}$ is removed from each nightly averaged temperature profile.

\section{Comparison with the CIRA-86 model}

The difference of the PCL climatology from the CIRA climatology is shown in Fig. 3. For most of the year below about $40 \mathrm{~km}$, the PCL temperature is more than $5 \mathrm{~K}$ colder than CIRA. At $60 \mathrm{~km}$ the PCL temperatures vary from being $5 \mathrm{~K}$ warmer than CIRA in winter to being just a few degrees warmer in the summer. However, it is above $70 \mathrm{~km}$ where the PCL climatology shows the most significant differences from the CIRA model. A band running from $85 \mathrm{~km}$ in mid February down to $73 \mathrm{~km}$ in the summer and rising back up to $85 \mathrm{~km}$ in November-December, is significantly colder (up to $17 \mathrm{~K}$ ) than the CIRA model. Above this cold band the PCL temperatures rise more quickly than the CIRA temperatures leading to the PCL temperatures being $20 \mathrm{~K}$ hotter than CIRA at about $93 \mathrm{~km}$ in the summer. These upper mesosphere and lower thermosphere temperature differences are a direct consequence of the PCL climatology having a significantly lower mesopause than the CIRA model (Table 3). 


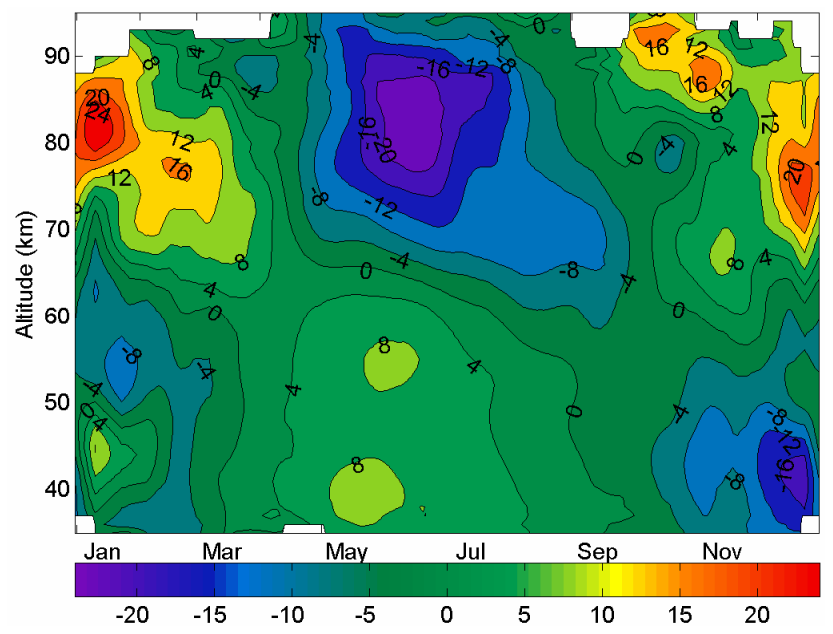

Fig. 4. Daily mean deviation from the annual mean temperature for the PCL climatology.

\section{Annual variations}

The deviation from the annual mean temperature for the PCL climatology is shown in Fig. 4. At an altitude of about $62 \mathrm{~km}$ the annual mean temperature varies by less than $10 \mathrm{~K}$ throughout the year. Below this altitude the temperatures are in phase with the absorption of solar radiation primarily by ozone. Above this altitude large scale dynamical processes lead to temperature changes which are out of phase with the solar energy input. The effect of these dynamical processes on temperature reaches a maximum at $83 \mathrm{~km}$ where the average temperature varies by more than $45 \mathrm{~K}$ over the year with the maximum temperature occurring in January and the minimum occurring 5 months later in June. Above $85 \mathrm{~km}$ the amplitude of this out-of-phase temperature variation starts to decrease with altitude as, once again, direct solar heating effects increase in importance. These effects can be clearly seen in Fig. 5, which shows the amplitude and phase of the annual oscillation. The amplitude and phase of the annual oscillation was determined by fitting a sine wave of variable amplitude and phase to the deviations for the annual mean at each altitude level using an iterative least-squares fitting procedure. Figure 5 a shows that at $62 \mathrm{~km}$ there is a minimum in the amplitude of the annual oscillation of about $2.5 \mathrm{~K}$. At this altitude there is also a sharp change in the phase of the annual oscillation (Fig. 5b), changing from summer below to winter above. The phase and amplitude of the PCL annual oscillation are generally consistent with those of the CEL+OHP and CSU lidar presented by Leblanc et al. (1998).

The determination of the characteristics of the semi-annual oscillation in the PCL temperature measurements is heavily influenced by the inversion induced perturbations in the December-February period. Measurements during this period are limited (see Table 2), not only in the number of measurements available but also the years in which the measure-
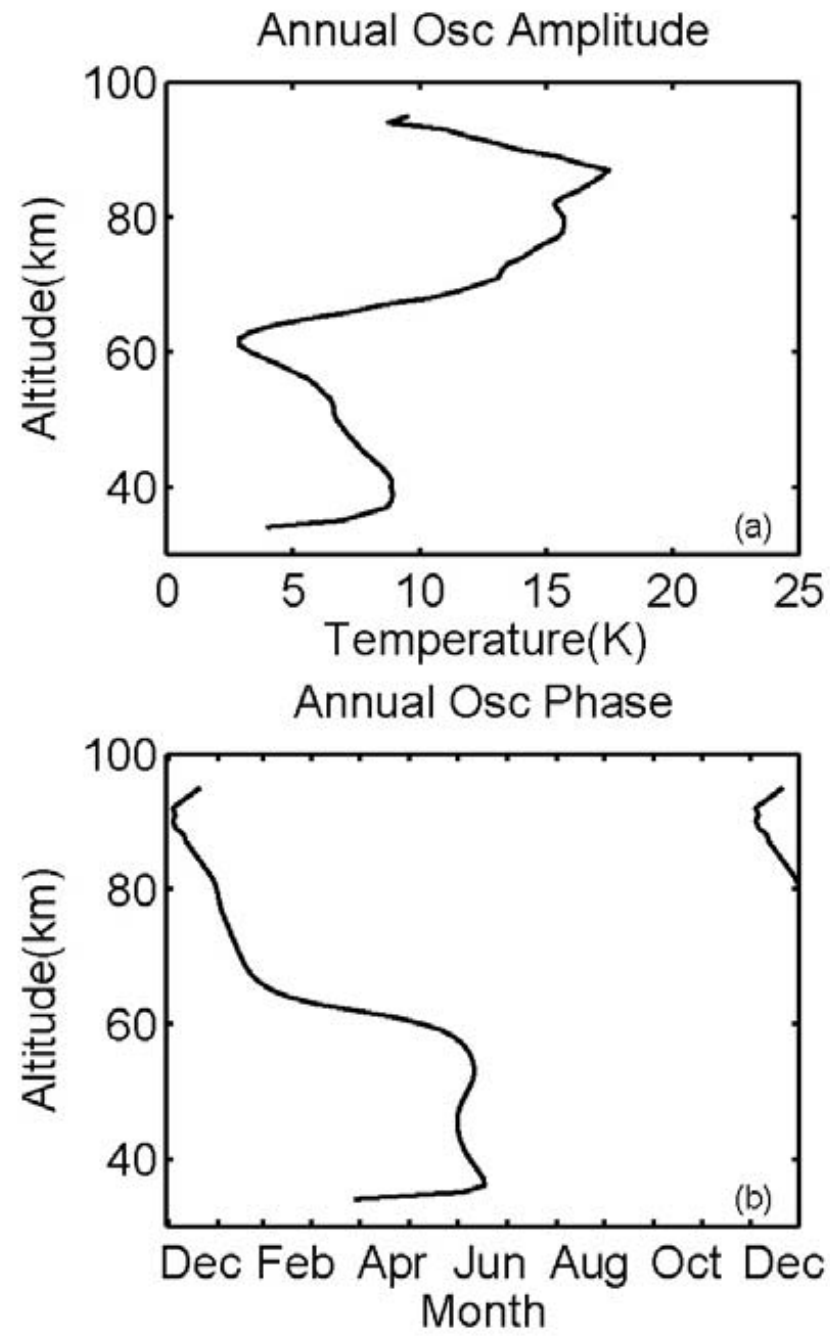

Fig. 5. Amplitude and phase of the annual oscillations calculated from the PCL temperature climatology.

ments are distributed. This makes the estimation of the characteristic of the semi-annual oscillation difficult and subject to error; for this reason no semi-annual oscillation characteristics are reported here.

\section{Shorter-scale variability}

As well as considering the average temperature climatology, it is also informative to look at the variability of the temperature as a function of altitude and time of year. Variability was determined by taking the daily standard deviation of the 33-day averaged temperature using the temperature profiles from each individual night, as opposed to the composite year which averages together measurement taken on the same night in different years. Taking each day number in turn, the standard deviation of all temperature profiles within 16 days either side of the day number is calculated. The 


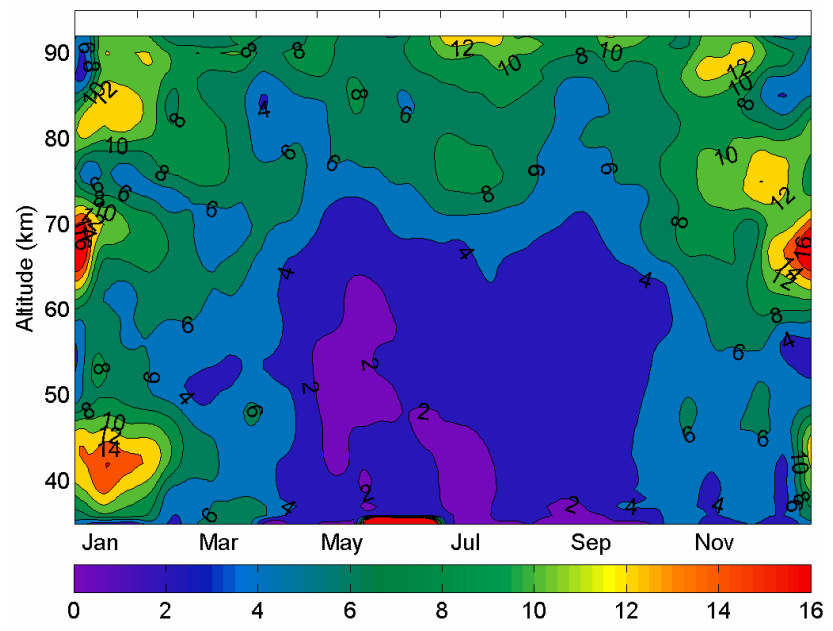

Fig. 6. Geophysical variability in temperature for the PCL climatology. The geophysical variability is the difference between the standard deviation of the 33 day averaged temperature and the measurement variability, as described in the text.

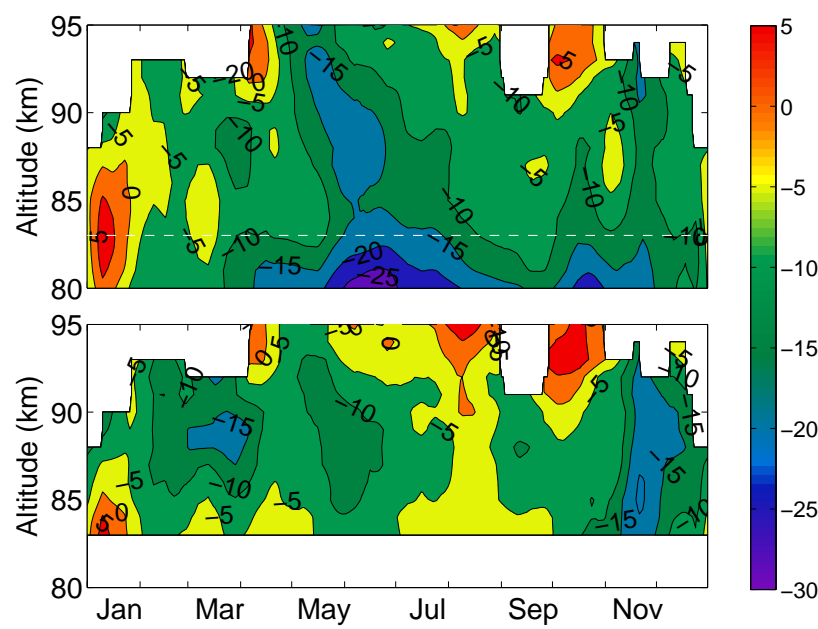

Fig. 7. PCL temperature climatology difference from the URB Na lidar climatology (top) and the CSU Na lidar climatology (bottom). The dashed white line on the URB climatology at $83 \mathrm{~km}$ indicates the lower altitude extent of the CSU climatology.

standard deviations, one for each day number, calculated in this way include the effects of both geophysical and measurement variability (predominantly photon counting noise). The measurement variability, which is only significant near the top of the individual temperature profiles, is calculated by taking the mean of the statistical uncertainties of the individual temperature profiles. The measurement uncertainties in the temperature profiles are the result of the propagation of the photon counting noise through the temperature retrieval algorithm. The square of the geophysical variability in the temperature is determined by subtracting the square of the measurement variability from the square of the 33-day stan-

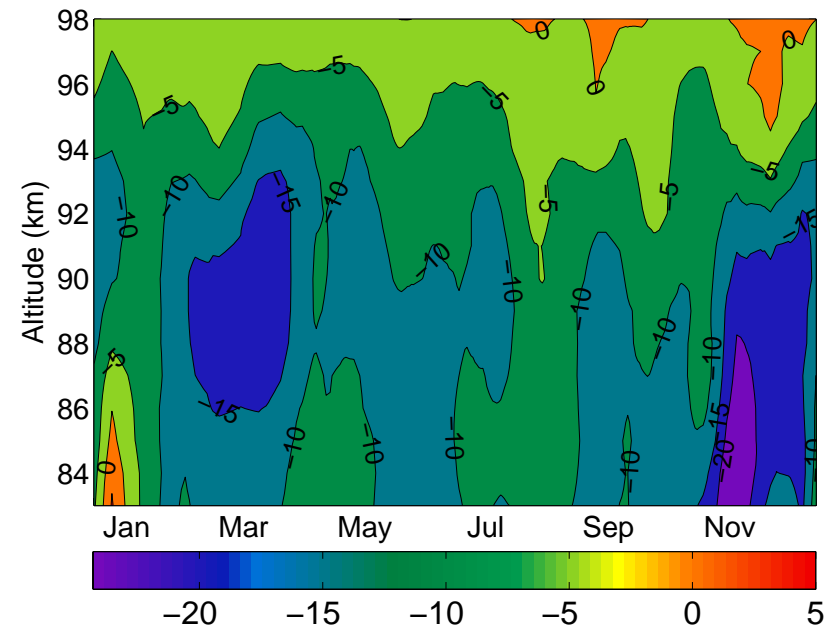

Fig. 8. Differences between the PCL and CSU temperature climatologies when the PCL temperature retrieval uses the CSU climatology for temperature retrieval integration initialization.

dard deviation. The geophysical variability calculated in this way is a measure of the variability associated with fluctuations or waves with periods ranging from 2 days (limited by nightly averaging of the temperature profiles used) to 33 days.

There is remarkably little variability in the temperature during the period from early April to the end of September in the altitude range from 35 to $65 \mathrm{~km}$ (Fig. 6). In this region the geophysical variability is typically less than $4 \mathrm{~K}$ indicating that wave activity for waves with periods longer than 2 days was extremely limited. During this same period above $70 \mathrm{~km}$, the temperature variability in the PCL climatology is a few degrees lower than that of the OHP+CEL climatologies. In the altitude range from 80 to $85 \mathrm{~km}$ there are minima in the temperature variability in both late March and mid September. The timing of these minima is in fairly good agreement with those reported by Leblanc et al. (1998), who found corresponding minima in late March and late September.

A peak in the 33 day temperature variability at $41 \mathrm{~km}$ in January is associated with stratospheric warmings (Leblanc et al., 1998) which often occur at about this altitude in the winter. Above this altitude a minimum in the variability is seen at $55 \mathrm{~km}$. At even greater altitudes the effects of mesospheric temperature inversions appear as an increase in the temperature variability. The PCL climatology shows this upper peak to extend from 60 to $75 \mathrm{~km}$ while the OHP+CEL and CSU climatologies presented by Leblanc et al. (1998) show it to extend to over $90 \mathrm{~km}$. This difference is likely due to limited number of December and January PCL measurements. 


\section{Comparisons with sodium resonance fluorescence li- dar climatologies}

The PCL Rayleigh lidar temperature climatology extends to sufficiently high altitudes to allow comparison with sodium lidar climatologies. She et al. (2000) as well as States and Gardner (2000) have published climatologies from the CSU and Urbana, IL (URB) sodium lidars respectively. The CSU climatology is derived from measurement taken between 29 May 1991 and 30 March 1999. For comparison with the PCL climatology we have used the CSU climatology with the episodic warming of 1993 removed. With 1993 removed this climatology is typically about $4 \mathrm{~K}$ colder than the climatology for all years. The URB climatology incorporates measurements from February 1996 to January 1998; for this comparison the URB night time only climatology is used.

The difference of the PCL temperature climatology from those obtained at CSU and URB is shown in Fig. 7. There exist significant differences between the CSU and URB climatologies and the PCL climatology, which is several degrees colder than both sodium climatologies. The overall average difference between the $\mathrm{Na}$ lidar climatologies above $83 \mathrm{~km}$ and the PCL climatology is $-7.0 \mathrm{~K}$ for the $\mathrm{CSU}$ and $-7.4 \mathrm{~K}$ for the URB climatology. There exist only two short periods when the PCL temperatures exceeded those measured by the Na lidars, in January up to about $85 \mathrm{~km}$ and in October above $90 \mathrm{~km}$. This difference is significant even given that the variability in temperature for time-scales greater than 2 days in the PCL climatology (Fig. 6) is about this same magnitude for most of the Spring, Summer and Fall. There exists the possibility that the tidal influence is different in the individual data sets but only if there is a substantial difference in the average local time over which measurements were made. However, this is not expected to be significant as the operating methods of the lidar groups is expected to be similar with the majority of measurements being made in the early to middle of the night with some extending until sunrise.

Leblanc et al. noted that the OHP+CEL temperatures show significant differences from the CSU climatology, though the CSU climatology used by Leblanc et al. is an older version of the CSU climatology than is used in this study. They suggested that the differences could be due to the initialization of the temperature retrieval algorithm using CIRA-86, which is known to be too cold in the altitude range where the $\mathrm{OHP}+\mathrm{CEL}$ temperatures were initialized. As previously explained the integration initialization has only a small effect on the PCL temperatures, typically less than $1 \mathrm{~K}$ (Fig. 2) since the top $10 \mathrm{~km}$ are removed from each nightly averaged temperature profile.

In order to further investigate the differences between the CSU and PCL climatologies a new PCL climatology was calculated. The nightly average temperature profiles used to form this climatology were calculated using the CSU temperatures at $98 \mathrm{~km}$ to seed the PCL temperature retrieval algorithm. No data was removed from the top of the calculated temperature profiles so that at $98 \mathrm{~km}$ the PCL climatology was forced to agree with the CSU climatology. Only profiles extending to $98 \mathrm{~km}$ or higher were used to form this climatology. Figure 8 shows the difference between the CSU seeded PCL climatology and the CSU climatology. Again the PCL climatology is significantly colder than the CSU climatology confirming that seeding the temperature retrieval using CIRA is not the cause of the differences in these climatologies.

\section{Discussion}

The retrieval of temperature profiles from Rayleigh-scatter measurements in the mesosphere and lower thermosphere depends on a few assumptions. No evidence exists to question the applicability of the Ideal Gas Law in this region of the atmosphere. The retrieval technique also relies on the assumption that the atmosphere is in hydrostatic equilibrium. Though gravity waves can have profound effects on this region of the atmosphere, the measurements used in this work, as well as those published for the Na lidar systems, are averages over extended periods (e.g. hours), which should minimize any gravity waves effects, particularly when many nights are combined into a monthly average. Another possible bias of the Rayleigh technique is the assumption of a "seeding" pressure to allow the retrieval of temperature from relative density, but as has been shown in the preceding section the temperature difference between London, Urbana and Fort Collins persists even when $\mathrm{Na}$ lidar measurements are used to seed the Rayleigh lidar measurements.

Possible explanations of the cause of the differences between the Na lidar and PCL-Rayleigh climatologies include a fundamental limitation of one of the two techniques. Argall et al. (2000) shows three examples of coincident Rayleigh and Na lidar temperature measurements using the PCL system. While the difference between these measurements is significant at some altitudes (i.e. greater than $10 \mathrm{~K}$ ) the variability between the 3 sets of measurements is such that it is impossible to draw any conclusions about systematic differences between the $\mathrm{Na}$ and Rayleigh temperatures.

Another possible issue with the Rayleigh-scatter measurements is the effects of composition on the Rayleighscatter cross section and the mean molecular mass, which is taken as a constant equal to its value at the surface. Mwangi et al. (2001) have used small differences in coincident Rayleigh-scatter backscatter and $\mathrm{Na}$ lidar temperature measurements to retrieve profiles of molecular oxygen and nitrogen in the mesosphere and lower thermosphere. Though only a few coincident nights measurements were available, no large, systematic trends were present. We have also calculated possible affects of composition changes on the temperatures due to reasonable changes in the mean molecular mass and found this to be negligible below $105 \mathrm{~km}$ (Argall, 2007). 
The other possible cause of the differences is geographic location. CEL $(44.0 \mathrm{~N}, 1.0 \mathrm{~W})$ and OHP $(44.0 \mathrm{~N}, 6.0 \mathrm{E})$ are at very similar latitudes $\left(1.1^{\circ}\right.$ difference) to the PCL $(42.9 \mathrm{~N}$, $81.4 \mathrm{~W}$ ) but at very different longitudes and these climatologies agree well. CSU $(40.6 \mathrm{~N}, 105.1 \mathrm{~W})$ and URB $(40 \mathrm{~N}$, $88 \mathrm{~W}$ ) are at slightly lower latitudes than CEL, OHP and PCL $\left(\sim 2.7^{\circ}\right.$ difference), but are $17.1^{\circ}$ different in longitude. While the CSU and URB climatologies show some differences, as much as $10 \mathrm{~K}$ in some small height-time intervals, the difference in the overall average of these climatologies is only $\sim 0.4 \mathrm{~K}$. This difference is much smaller than the difference between the Na lidar climatologies and the PCL climatology.

Hocking et al. (2007) have compared temperature measurements from the Purple Crow Lidar, temperatures derived from airglow measurements of hydroxl and temperatures derived from the fading of meteor echoes using the CLOVAR radar. All three instruments were located within $20 \mathrm{~km}$ of each other. Using coincident nights of measurements for the radar and lidar (a data set biased to the summer months) Hocking et al. (2007) found that in the $85 \mathrm{~km}$ region the temperatures were within $1 \mathrm{~K}$ of each other. In the $91 \mathrm{~km}$ region the lidar temperatures were $\sim 5 \pm 3 \mathrm{~K}$ cooler than the radar temperatures.

The Na temperature technique has been carefully quantified in terms of system and geophysical effects (She et al., 1994; Papen et al., 1995). The general overall quality of these measurements corresponds to an accuracy of about $1 \mathrm{~K}$ and statistical errors on the order of 1 to $2 \mathrm{~K}$ near the peak of the Na layer. A limitation to be aware of for the Na measurements is that the rapid decrease of the Na density below the peak leads to a significant increase in the statistical errors in this region. However, for the climatologies presented this effect should small due to averaging over several hours of measurements.

It appears to be more likely there is a geophysical reason for the temperature difference. A possible chemical-based explanation for the temperature differences would involve differences in abundance of atomic oxygen, but it is difficult to imagine such large differences for such extended periods would exist. Possible dynamical explanations for the temperature difference could involve a large-scale, persistent wave structure, e.g. a tide or planetary wave, which could have a temporal variation such that around local midnight (the midpoint of most lidar observations), the temperature is consistently colder west of London in the $85 \mathrm{~km}$ altitude region.

The consistent different in temperature could also be a results of differences in gravity-wave activity between the locations. The upper mesosphere above southwestern Ontario appears to have a large amount of energy deposition due to gravity waves, in part due to atmospheric effects resulting from the proximity of London between Lake Huron and Lake Erie. However, Fort Collins is on the lee side of the Rocky Mountains, so one would expect periods of large wave breaking events due to flow over the mountains to occur frequently. It may be necessary to use either long term colocated $\mathrm{Na}$ and Rayleigh lidar temperature measurements or another technique, i.e. meteor radar temperatures (Hocking et al., 2004) or satellite based measurements (Kerzenmacher et al., 2005; Wu et al., 2003) to determine the source and cause of the differences in these climatologies.

\section{Summary}

1. The PCL and OHP+CEL climatologies are remarkably similar throughout the entire range of their overlap (35 to $85 \mathrm{~km}$ ), given the longitudinal separation of the sites, as well as the difference in orography around these sites. The mesopause altitude and temperature in the CIRA-86 model are significantly different from those seen in the PCL climatology. In all but the Summer months, when the PCL climatology does not extend to the mesopause, the PCL measured mesopause is several kilometres lower than the CIRA-86 mesopause.

2. The 2 to 33 day temperature variability above $70 \mathrm{~km}$ for the months from June to September is a few degrees lower in the PCL than for the OHP+CEL climatology. This could be in part due to differences in the methods used to determine the variances.

3. The daily mean deviation from the annual mean temperature for the PCL climatology shows similar features to the composite climatology produced with OHP+CEL, CSU and URB measurements, showing that not surprisingly, zonal seasonal changes occur similarly on a global scale.

4. The phase and amplitude of the annual oscillations determined from the PCL measurements are in line with those of the lidar climatologies presented by LeBlanc et al.

5. The geophysical variability in temperature is $4 \mathrm{~K}$ or less from 35 to $70 \mathrm{~km}$ from April to October. In the winter the mesospheric inversions perturb the temperature and significantly increase the variability.

6. The climatologies derived from the Na lidars at CSU and URB show significant temperature differences with the PCL climatology (about $7 \mathrm{~K}$ colder), which are not related to the seeding of the temperature retrieval algorithm.

\section{Conclusions}

The overall good agreement between the Rayleigh-scatter lidar temperature measurements in Canada and France at similar latitudes in the 35 to $85 \mathrm{~km}$ region is surprising given the large longitudinal separation of the stations. While one 
might expect reasonable agreement between the middle atmospheric temperature climatologies at these two sites, due to zonal symmetry, one might also expect that dynamical activity due to large-scale waves would cause some differences between locations in terms of annual oscillations and shorter period variability. That being said, the significant temperature differences between the sodium resonance fluorescence measurements in the central and western United States compared to the Rayleigh-scatter lidar measurements at a similar latitude is surprising, and not easy to explain in terms of limitations or errors in the measurement techniques. The best resolution to this conundrum would be long term colocated Rayleigh and $\mathrm{Na}$ lidar temperature measurements, which would allow a direct comparison of these two techniques, possibly providing an answer to this mystery.

Acknowledgements. We would like to thank Canada's National Science and Engineering Council (NSERC) for provided funding for this work. We would also like to thank T. Leblanc for providing testing of the PCL Rayleigh temperature retrieval routines and for the suggestions he made for the improvement of these routines.

Topical Editor U.-P. Hoppe thanks C.-Y. She and another referee for their help in evaluating this paper.

\section{References}

Argall, P. S.: Upper altitude limit for Rayleigh lidar, Ann. Geophys., in press, 2007.

Argall, P. S., Vassiliev, O. N., Sica, R. J., and Mwangi, M. M.: Lidar measurements taken with a large-aperture liquid mirror: 2 . The Sodium resonance-fluorescence system, Appl. Opt., 39, 23932399, 2000.

Clancy, R. T. and Rusch, D. W.: Climatology and Trends of Mesospheric $(58-90 \mathrm{~km})$ temperature based upon 1982-1986 SME limb scattering profiles, J. Geophys Res., 94, 3377-3393, 1989.

Clancy, R. T., Rusch, D. W., and Callan, M. T.: Temperature Minima in the average Thermal Structure of the Middle Atmosphere $(70-80 \mathrm{~km})$ from analysis of the 40- to $92-\mathrm{km}$ SME global temperature profiles, J. Geophys Res., 99, 19001-19020, 1994.

Fleming, E. L., Chandra, S., Barnett, E. L., and Corney, M.: Zonal mean temperature, pressure, zonal wind and geopotential height as functions of latitude, Adv. Space Res., 10, 11-59, 1990.

Hauchecorne, A. and Chanin, M. L.: Density and Temperature profiles obtained by Lidar between 35 and $70 \mathrm{~km}$, Geophys. Res. Lett., 7, 565-568, 1980.

Hocking, W. K., Singer, W., Bremer, J., Mitchell, N. J., Batista, P., Clemesha, B., and Donner, M.: Meteor radar temperatures at multiple sites derived with SKiYMET radars and compared to $\mathrm{OH}$, rocket and lidar measurements, J. Atmos. Sol. Terr. Phys., 66, 585-593, 2004.

Hocking, W. K., Argall, P. S., Lowe, R. P., Sica, R. J., and Ellinor, H.: Height Dependent Meteor Temperatures and Comparisons with Lidar and OH measurements, Can. J. Phys., accepted, 2007.

Leblanc, T., McDermid, I. S., Hauchecorne, A., and Keckhut, P.: Evaluation of optimization of lidar temperature analysis algorithms using simulated data, J. Geophys. Res.-Atmos., 103, 6177-6187, 1998.
Mwangi, M. M., Sica, R. J., and Argall, P. S.: Retrieval of molecular nitrogen and molecular oxygen densities in the upper mesosphere and lower thermosphere using ground-based lidar measurements, J. Geophys. Res.-Atmos., 106, 10313-10323, 2001.

Kerzenmacher, T. E., Walker, K. A., Strong. K., Berman, R., Bernath, P. F., Boone, C. D., Drummond, J. R., Fast, H., Fraser, A., MacQuarrie, K., Midwinter, C., Sung, K., McElroy, C. T., Mittermeier, R. L., Walker, J., and Wu, H. J.: Measurements of O-3, NO2 and temperature during the 2004 Canadian Arctic ACE Validation Campaign, Geophys. Res. Lett, 32, L16S07, doi:10.1029/2005GL023032, 2005.

Leblanc, T., McDermid, I. S., Keckhut, P., Hauchecorne, A., She, C. Y., and Krueger, D. A.: Temperature climatology of the middle atmosphere from long-term lidar measurements at middle and low latitudes, J. Geophys. Res., 103, 17 191-17 204, 1998.

Leblanc T., McDermid, I. S., Hauchecorne, A., and Keckhut, P.: Evaluation of optimization of lidar temperature analysis algorithms using simulated data, J. Geophys. Res., 103, 6177-6187, 1998.

Liu, H. L. and Meriwether, J. W.: Analysis of a temperature inversion event in the lower mesosphere, J. Geophys. Res.-Atmos., 109, D02S07, doi:10.1029/2002JD003026, 2004.

Papen, G. C., Pfenninger, W. M., and Simonich, D. M.: Sensitivity Analysis of Na Narrow-Band Wind-Temperature Lidar Systems, Appl. Opt., 24, 480-498, 1995.

Randel, W., Udelhofen, P., Fleming, E., Geller, M., Gelman, M., Hamilton, K., Karoly, D., Ortland, D., Pawson, S., Swinbank, R., Wu, F., Baldwin, M., Chanin, M. L., Keckhut, P., Labitzke, K., Remsberg, E., Simmons, A., and Wu, D.: The SPARC intercomparison of middle-atmosphere climatologies, J. Climate, 17, 986-1003, 2004.

She, C. Y. and Yu, J. R.: Simultaneous 3-Frequency Na Lidar Measurements of Radial Wind and Temperature in the Mesopause Region, Geophys. Res. Lett., 21, 1771-1774, 1994.

She, C. Y., Chen, C., Hu, Z., Sherman, J., Vance, J. D., Vasoli, V., White, M. A., Yu, J., and Krueger, D. A.: Eight-year climatology of nocturnal temperature and sodium density in the mesopause region (80-105 km) over Fort Collins, CO (41 N, $105 \mathrm{~W})$, Geophys. Res. Lett., 27, 3289-3292, 2000.

Sica, R. J., Sargoytchev, S., Argall, P. S., Borra, E., Girard, L., Sparrow, C. T., and Flatt S.: Lidar measurements taken with a large-aperture liquid mirror: 1. The Rayleigh-scatter system, Appl. Opt., 340, 6925-6936, 1995.

Sica, R. J., Argall, P. S., Russell, A. T., Bryant, C. R., and Mwangi, M. M.: Dynamics and composition measurements in the lower and middle atmosphere with the Purple Crow Lidar, Recent Research Developments in Geophysical Research, 3, 1-16, 2000.

Sica, R. J., Zylawy, Z., and Argall, P. S.: Ozone Corrections for Rayleigh-Scatter Temperature Determinations in the Middle Atmosphere, J. Atmos. Ocean. Tech., 18, 1223-1228, 2001.

States, R. J. and Gardner, C. S.: Thermal structure of the mesopause region $(80-105 \mathrm{~km})$ at 40 degrees N latitude. Part I: Seasonal variations, J. Atmos. Sci., 57, 66-77, 2000.

Wu, D. L., Read, W. G., Shippony, Z., Leblanc, T., Duck, T. J., Ortland, D. A., Sica, R. J., Argall, P. S., Oberheide, J., Hauchecorne, A., Keckhut, P., She, C. Y., and Krueger, D. A.: Mesospheric temperature from UARS MLS: retrieval and validation, J. Atmos. Sol. Terr. Phys., 65, 245-267, 2003. 